\title{
Editorial: Restoration of Degraded Terrestrial Ecosystems
}

\author{
Nadia S. Santini ${ }^{1 *}$, Sonia Chamizo ${ }^{2}$, Manuel Esteban Lucas-Borja ${ }^{3}$ and \\ Miriam Muñoz-Rojas ${ }^{4,5}$ \\ ${ }^{1}$ Programa de Investigadoras e Investigadores por México, Instituto de Ecología, Universidad Nacional Autónoma de México, \\ Mexico City, Mexico, ${ }^{2}$ Departamento de Agronomía, Universidad de Almería, Almería, Spain, ${ }^{3}$ Universidad de Castilla-La \\ Mancha, Escuela Técnica Superior de Ingenieros Agronomos y de Montes de Albacete Campus Universitario s/n C.P. 02071, \\ Albacete, Spain, ${ }^{4}$ Centre for Ecosystem Science, School of Biological, Earth, and Environmental Sciences, University of \\ New South Wales, Sydney, NSW, Australia, ${ }^{5}$ Department of Plant Biology and Ecology, University of Seville, Seville, Spain
}

Keywords: drylands, ecosystem shifts, Mediterranean region, mining, Amazonian rainforest

\section{Editorial on the Research Topic}

\section{Restoration of Degraded Terrestrial Ecosystems}

Land degradation is caused by human activities that exploit, degrade or pollute land and soil (Keesstra et al., 2018). This can disrupt ecosystems, resulting in the loss of biodiversity and ecosystem services that support food production and the livelihoods of dependent populations (IPBES, 2019). Land degradation can also release soil carbon into the atmosphere making a significant contribution to climate change (Webb et al., 2017). This special issue focuses on the impact of land degradation on terrestrial habitats and efforts to reverse this impact and restore ecosystems.

Land degradation already impacts approximately $75 \%$ of the land on Earth and continues to accelerate in recent years due to combined pressures of agricultural and livestock grazing, urbanization, and deforestation, among other intensive land-uses (IPBES, 2019). Given the importance of a healthy land for human prosperity, the United Nations declared 2021-2030 the "Decade on Ecosystem Restoration" to halt the further degradation of ecosystems and to restore the amount and quality of land resources necessary to support biodiversity, ecosystem functions, and services. Achieving this goal will require innovative and sustainable solutions that consider ecological, social, and economic needs (Willemen et al., 2020).

Land degradation is driven by many causes, and different ecosystems face diverse challenges (Wuepper et al., 2021). This special issue includes eight studies that consider the impact of land degradation on diverse ecosystems across the globe, from the Amazonian jungle in Brazil to the grasslands of Africa. Each article aims to understand the causes and solutions to land degradation in each ecosystem.

Arid and semi-arid rangelands are key ecosystems under the increasing threat of desertification worldwide (Bestelmeyer et al., 2015). They are primarily covered by grass and shrubs and receive low and intermittent rainfall. These drylands maintain high biodiversity and are the basis for pastoral grazing that supports many populations, with livestock traversing the rangelands searching for water and grazing. However, increasing desertification, often driven by overgrazing, is eroding the grasslands (Huang et al., 2016).

A simple solution to prevent further degradation is the use of grazing enclosures that exclude livestock and allow grasslands to recover. However, the success of these structures has been mixed. Fenetahun et al. evaluated the success of grazing enclosures on the grassland diversity and biomass in the Borana rangelands, which form one of the largest pastoral bases in Ethiopia and have been severely degraded by over-grazing. By comparing the impact of long- and short-term grazing 
enclosures, rotational grazing, and re-seeding, Fenetahun et al. were able to develop effective strategies for sustainable management of grazing in these grasslands.

The recovery of grasslands from land degradation may be accelerated by active solutions, such as re-seeding with native grasses. However, the successful re-establishment and growth of re-seeded grasses are challenging. To understand these conditions, Mganga et al. performed extensive field studies in semi-arid rangelands in Southern Kenya to evaluate the advantages of different native perennial grasses for re-seeding. By measuring morpho-ecological traits, including the growth of above- and below-ground biomass, and their interaction with weeds and water use efficiency, Mganga et al. optimized the selection of native grassland species best suited to achieve desired restoration outcomes across African rangelands.

Despite these efforts, the rehabilitation of dryland ecosystems is often difficult due to constraining environmental pressures, such as intermittent rainfall, that limits restorative vegetation growth and survival. Maggioli et al. investigated whether restoration of dryland ecosystems could be improved by an optimal design of biocrust-vegetation spatial distribution that maximizes water and nutrient capture by plants. Through the application of a spatially distributed runoff and erosion model on a degraded hillslope from a limestone quarry in south-eastern Spain, Maggioli et al. found that location of vegetation in the areas of higher water accumulation as well as active biocrust restoration by cyanobacteria inoculation was the most efficient configuration in reducing runoff and erosion and increasing water availability to plants, thus, providing a useful approach to increase restoration success in drylands.

The effective management of land use, including government legislation and policies, is needed to address land degradation. The arid temperate grassland steppes of Mongolia and Inner Mongolia are threatened by overgrazing, and their growing desertification results in increasingly severe dust storms that blow across Asia. Yong et al. analyzed the land factors, such as vegetation coverage and soil moisture, that controlled dust emissions over the past three decades. They then considered the success of recent land-use legislation for the protection of grasslands and the reduction of the frequency and severity of dust storms.

Whilst land degradation is often a gradual process, when ongoing pressures exceed the tolerance thresholds, the ecosystem may no longer be able to recover, resulting in a catastrophic ecosystem shift. This dramatic and irreversible shift to a degraded state can occur suddenly and rapidly, with little warning, and results in major losses to biodiversity, ecosystem functioning and resilience. van den Elsen et al. investigated catastrophic ecosystem shifts that have occurred across multiple forested and grassland sites across the Mediterranean region. The vegetation and soil composition and quality at degraded sites were compared to non-degraded reference ecosystems to identify conditions that predict the proximity of an ecosystem to the catastrophic threshold and were then used to model the success of alternative management strategies to prevent catastrophic shifts.

In the drylands of Australia, mining operations are a primary cause of land degradation. The rehabilitation of a mine site typically uses topsoil and other available substrates to reconstruct soils. However, these substrates often contain waste materials and tailings that prevent the establishment and growth of new seedlings. Stock et al. investigated using extruded pellets containing seeds mixed with soil and adding organic amendments to improve seedling growth in these reconstructed soils. By evaluating the success of seedling emergence, this approach showed promise compared to current practices for rehabilitating mining sites across north-western Australia.

Land degradation and desertification impact the livelihood of more than 3 billion people worldwide, reducing ecosystem services including the provision of food and water resources and pressuring populations to move to more hospitable regions. To understand this relationship between land degradation and livelihood, Sharafatmandrad and Khosravi Mashizi compared the degradation of a semi-arid rangeland in southeast Iran with the socio-economic wellbeing of resident populations. In these rangelands, Sharafatmandrad and Khosravi Mashizi found land degradation and measures of social wellbeing were linked and showed how the value of ecosystems must be aligned with population requirements to ensure long-term, sustainable land restoration that considers ecological, social and economic needs.

Reconciling the often-opposing ecological requirements of terrestrial habitats with the socioeconomic needs of populations is challenging. Gastauer et al. examined the current gap between these ecological and socio-economic requirements in the Amazon rainforest, which is undergoing rapid deforestation. They argue that the environmental regularization of rural properties, local community engagement, implementing sustainability policies, such as certified timber and forestry and agriculture diversification, and incentivizing seed and seedling supply is needed to support restoration efforts. These efforts must be further monitored using standardized, large-scale satellite data to ensure accountability, and learn from success and failures.

Land degradation is one of our foremost challenges, and there is a pressing need for further research into causes, management, and solutions to restore ecosystems. The studies within this issue provide key insights into the different causes of land degradation, from overgrazing, limited water availability, or mining operations. Furthermore, these studies offer tractable solutions to halt degradation, including the re-seeding of grasslands, the rotation of grazing, the retention of water and nutrients, and informed government legislation and land-use management. Without these efforts, ecosystems will eventually undergo catastrophic ecosystem shifts from which they cannot recover, resulting in lost biodiversity and the key ecosystem services upon which large populations depend. Whilst each study provides an illustrative example of the causes and solutions to land-degradation in a single ecosystem, collectively, they demonstrate the required scale and innovation of solutions needed to urgently reverse this trend and assure the health of our terrestrial landscapes.

\section{AUTHOR CONTRIBUTIONS}

All authors listed have made a substantial, direct, and intellectual contribution to the work and approved it for publication. 


\section{REFERENCES}

Bestelmeyer, B. T., Okin, G. S., Duniway, M. C., Archer, S. R., Sayre, N. F., Williamson, J. C., et al. (2015). Desertification, land use, and the transformation of global drylands. Front. Ecol. Environ. 13, 28-36. doi: 10.1890/140162

Huang, J., Yu, H., Guan, X., Wang, G., and Guo, R. (2016). Accelerated dryland expansion under climate change. Nat. Clim. Change 6, 166-171. doi: $10.1038 /$ nclimate 2837

IPBES (2019). Global Assessment Report of the Intergovernmental Science-Policy Platform on Biodiversity and Ecosystem Services, eds E. S. Brondízio, J. Settele, S. Díaz, H. T. Ngo (Bonn: IPBES secretariat), 1144.

Keesstra, S., Mol, G., de Leeuw, J., Okx, J., Molenaar, C., de Cleen, M., et al. (2018). Soil-related sustainable development goals: four concepts to make land degradation neutrality and restoration work. Land 7, 133 . doi: 10.3390/land7040133

Webb, N. P., Marshall, N. A., Stringer, L. C., Reed, M. S., Chappell, A., and Herrick, J. E. (2017). Land degradation and climate change: building climate resilience in agriculture. Front. Ecol. Environ. 15, 450-459. doi: 10.1002/fee.1530

Willemen, L., Barger, N. N., Brink, B., ten, Cantele, M., Erasmus, B. F. N., Fisher, J. L., et al. (2020). How to halt the global decline of lands. Nat. Sustain. 3, 164-166. doi: 10.1038/s41893-020-0 $477-\mathrm{x}$
Wuepper, D., Borrelli, P., Panagos, P., Lauber, T., Crowther, T., Thomas, A., et al. (2021). A 'debt' based approach to land degradation as an indicator of global change. Glob. Change Biol. 27, 5407-5410. doi: 10.1111/gcb.15830

Conflict of Interest: The authors declare that the research was conducted in the absence of any commercial or financial relationships that could be construed as a potential conflict of interest.

Publisher's Note: All claims expressed in this article are solely those of the authors and do not necessarily represent those of their affiliated organizations, or those of the publisher, the editors and the reviewers. Any product that may be evaluated in this article, or claim that may be made by its manufacturer, is not guaranteed or endorsed by the publisher.

Copyright $\odot 2022$ Santini, Chamizo, Lucas-Borja and Muñoz-Rojas. This is an open-access article distributed under the terms of the Creative Commons Attribution License (CC BY). The use, distribution or reproduction in other forums is permitted, provided the original author(s) and the copyright owner(s) are credited and that the original publication in this journal is cited, in accordance with accepted academic practice. No use, distribution or reproduction is permitted which does not comply with these terms. 